\title{
O NOME DAS PERSONAGENS EM CINZAS DO NORTE: UMA QUESTÃO POÉTICA
}

Lucilia Lúbia de Sousa Pinheiro ${ }^{1}$

Gunter Karl Pressler ${ }^{2}$

\begin{abstract}
RESUMO
O artigo apresenta a forma poética, de acordo com Meschonnic (2002), do nome das personagens em Cinzas do Norte (2005), partindo da intenção do autor abstrato em intensificar o nome da personagem principal Mundo, pois ao ser chamado constantemente de Mundo, a personagem transmite a experiência que ele vai ter para além de Manaus, do Norte, mas para o mundo. As experiências que Mundo terá a partir dessas viagens e do próprio contexto na obra o colocam como personagem de um romance de formação.
\end{abstract}

Palavras-Chave: Nome. Personagem. Cinzas do Norte. Poética.

\begin{abstract}
The article presents the poetic form, according to Meschonnic (2002), of the names of the characters in Northern Ashes (2005), starting from the intention of the abstract author to intensify the name of the main character Mundo. Being constantly called by the nickname Mundo (World), the character conveys the experience he will have beyond Manaus, from the North to the world. The experiences that Mundo will have from these trips, as well as the very context in the work, place him as a character in a formation novel. Keywords: Name. Character. Northern Ashes. Poetic.
\end{abstract}

Keywords: Name. Character. Northern Ashes. Poetic.

Recebido em: 10/08/2017

Aprovado em: 04/09/2017

\section{INTRODUÇÃO}

Milton Hatoum é reconhecido como um dos grandes exponentes da literatura brasileira contemporânea. Ganhador de vários prêmios literários, tem em sua biografia obras como, Relato de um certo Oriente (1989), Dois Irmãos (2000), Órfãos do Eldorado (2008), A cidade ilhada (2009), Um solitário à espreita (2013). O autor procurou trabalhar com aspectos que envolvem desde pequenos eventos cotidianos a referências históricas e sociológicas. Suas narrativas têm como cenário a região amazônica, sobretudo a cidade de Manaus.

\footnotetext{
${ }^{1}$ Universidade Federal do Pará. Mestranda em Estudos Literários (Capes/PPGL/UFPA). Email: lubiapinheiro@yahoo.com.br.

${ }^{2}$ Professor de Teoria Literária na Universidade Federal do Pará/UFPA. Programa de Pós-Graduação em Letras (PPGL), Programa de Pós-Graduação em Linguagens e Saberes da Amazônia (PPLSA). E-mail: gupre @ufpa.br.
} 
A epígrafe de João Guimarães Rosa, "Eu sou donde eu nasci, Sou de outros lugares", contida no livro "Cinzas do Norte" (2005), já demonstra toda carga significativa em cada elemento na narrativa.

Com Cinzas do Norte o cenário é o mundo, não por acaso o nome do personagem central é Mundo (Raimundo). Com a obra, o autor une o social ao existencial. O trabalho com o texto é vasto, pois assim como a literatura contemporânea, podemos encontrar vários elementos que dão sentido à obra.

Como observa Meschonnic (2002 p. 38) "o texto é uma relação com o mundo e com a história, portanto o estudo das obras é uma questão poética”. O nome do personagem Raimundo, cujo apelido é Mundo, foi escolhido pelo autor abstrato, porque atenta para essa relação, pois ao ser chamado constantemente de Mundo, a personagem transmite a experiência que ele vai ter para além de Manaus, do Norte, vislumbrando o mundo que lhe está adiante.

Mundo não queria seguir o destino que o pai queria para ele, não queria assumir os negócios da família. Repudiava qualquer ligação com o pai. Mundo queria ser artista, o artista que tinha um lema "ou a obediência estúpida, ou a revolta" (HATOUM, 2005, p. 10). Ele não se atém às amarras sociais e essa atitude é fundamental para a formação dele enquanto indivíduo, enquanto protagonista de um Romance Moderno de Formação.

\section{UM ROMANCE DE FORMAÇÃO}

Romance de formação, termo cunhado por Karl Morgenstern (SELBMANN, 1988), descreve aspectos do desenvolvimento pessoal do indivíduo a partir das experiências que ele enfrenta. Os anos de aprendizado de Wilhelm Meister, de Wolfgang von Goethe, no contexto do Romantismo e da Era Clássica da literatura alemã, publicado entre 1795-1796, tornou-se o modelo para uma série de romances posteriores que surgiriam. Segundo Rüdiger Safranski em seu livro, Romantismo uma questão alemã:

O Wilhelm Meister de Goethe havia trazido ao gênero do romance nova reputação, ele motivou a ambição da nova geração de poetas de criar também uma narrativa na qual estivessem interligados a representação do desenvolvimento de um indivíduo interessante, o esclarecimento de problemas do trabalho artístico e uma imagem global da sociedade. Depois do Wilhelm Meister o romance passa a ser um gênero poético universal, no qual tudo podia ter lugar, descrições da natureza, diversos palcos, confusões e conflitos, poemas espalhados, apresentados também sob a forma de diálogos e reflexões, psicologia, filosofia, teoria da arte. Se queria ir afundo com o romance. (SAFRANSKI, 2010, p. 98-99). 
A "formação" a partir do conceito romântico, diz respeito ao "desenvolvimento da subjetividade, da capacidade de percepção, reflexão e criação". O romance de formação, segundo Volobuef (1999, p. 44) "trata-se de uma busca de si mesmo, da libertação das amarras sociais (obediências aos pais e a instituições como o casamento, etc.), da descoberta de novas possibilidades de subsistência que não se restrinjam a profissões burguesas tidas como úteis".

A personagem é direcionada para um fim harmonioso, irônico, mas harmonioso. No entanto, percebemos que o que foi um mundo idealizado, o início, desmoronou no século XX (PRESSLER, 2002, p.23).

O desenvolvimento harmonioso no indivíduo não existe, ele fracassou. O Romance de formação assume um caráter diferente a partir do século XX, seria então um Romance Moderno de Formação, entendido como capacidade e habilidade de se encontrar no mundo fragmentado, desmoronado - identidades na superfície e no fragmento - "identidade irônica e/ou reflexiva" (PRESSLER, 2002, p. 23).

E Mundo integra o conjunto dessas personagens uma vez que, quando está em Manaus, no período de sua infância/adolescência tem uma postura rebelde, em que ao conversar com Palha, diz que não precisa frequentar a escola para obter conhecimento, conhecimento ele pode ter através dos livros e das obras dos artistas (HATOUM, 2005, p. 119).

A relação de Mundo com o pai nunca foi boa, falando em carta sobre o filho, o pai afirma que "[..] Mundo só se dá com caboquinhos, as crianças da vizinhança são filhos de casais distintos, mas ele só procura os selvagens" (HATOUM 2005, p. 251). Com o passar do tempo, a relação entre pai e filho se agrava "um pai não pode gostar mais de um cachorro do que de um filho" (HATOUM, 2005, p. 123).

E Mundo percebe que não precisa só se afastar de seu pai, como também de Manaus, o que consequentemente o leva a viagens para conhecer o mundo. O personagem, então, vai para a Europa, onde conhece grandes centros, como Londres e Berlin.

Aliás, no livro, de acordo com Amarílis Tupiassú (2016), não se pode esquecer:

o jogo de nomeação em Cinzas do Norte. Alícia, a que alicia e se fecha em segredos surpreendentes; Raimundo-Mundo o fulcro de todas, das grandes dores do mundo; Trajano, o imperador, reduzido a Jano, a centro de cegueira, enganos, infidelidades; Ranulfo, Ran, o desgarrado, o desassossego, que pula de charco em charco; Naiá, o nome indígena e pouco mais, a índia distribalizada, sem origem certa, sem família; Olavo, lavo, que te fato lava em silêncio a roupa suja, a consciência que purga, põe pra fora, lava com as armas da palavra (TUPIASSÚ, 2016, p. 167). 
Tal como Raimundo-Mundo tem seu significado, Hatoum mexe também com todos os personagens da trama do livro, em que cada um desempenha um papel social ou moral. Como no caso da índia Naiá, a sem tribo, sem identidade, que faz tudo na casa dos Matosos, ou no caso de Jano, o deus de duas faces ${ }^{3}$, aquele que não reina em casa, aquele cujo filho não obedece e cuja mulher trai.

Essa dupla faceta de Jano ao tratar bem Lavo e não fazer esforço, na visão de Mundo, para tratar bem o filho, leva a relação dos dois até as últimas consequências:

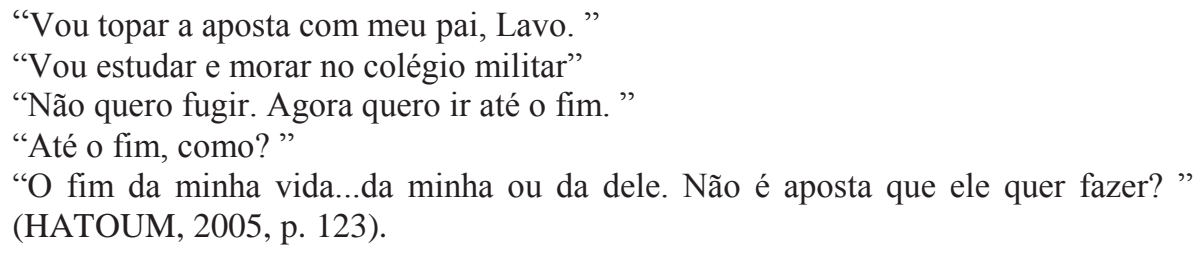

Ao ser levado pelo sentimento de comparação, Jano deixa claro que queria que o filho fosse igual ao amigo:

"Jano bateu no meu ombro esquerdo, pôs o dedo nas três divisas vedes costuradas na manga as camisa: 'Teu sobrinho promete coisa melhor...bem melhor que o tio e que meu filho, que até agora não promete nada'." (HATOUM, 2005, p. 21).

Ran, o desgarrado "subversivo" entendia o trabalho dele como o próprio fazer literário.

Lembro que, em plena tarde de um dia de semana, Ramira o encontrou lendo e fazendo anotações a lápis numa tira de papel de seda branco. Perguntou porque ele lia e escrevia em vez de ir atrás de trabalho. "Estou trabalhando, mana", disse tio Ran. "Trabalho com a imaginação dos outros e com a minha". Ela estranhou a frase, que algum tempo depois eu entenderia como uma das definições de literatura. (HATOUM, 2005, p. 24)

Trata-se de um dos trabalhos que ele assim considerava, pois Ran é o protótipo do indivíduo que vai de encontro aos valores institucionais, homem que não sabe viver "preso" em emprego ou casamento. Por isso, ele abandonou mulher e filho na Vila-Amazônica, tanto por não saber viver assim, quanto por ainda amar Alícia.

A vida de Ran é inventar o que fazer, não fazer planos. "Devias passar a vida lendo e vivendo por aí sem profissão. Vais acabar que nem tua tia, trancado numa saleta e rezando para conseguir um cliente...Ou então correndo de uma vara para outra" (HATOUM 2005, p.94). Assim, Ran repreende Lavo pela escolha em seguir a profissão de advogado. Para ele

\footnotetext{
${ }^{3}$ Segundo a mitologia romana, Jano é um deus de duas faces, uma voltada para o passado e outra para o futuro.
} 
nada na vida poderia compensar a liberdade de escolher o que fazer, mandar na sua própria vida.

Lavo, o narrador, nas palavras de Tupiassú (2016) “aquele que de fato lava” é o único na história que consegue ser alguém na vida. Lavo não fazia planos sobre o futuro, no entanto, estuda, cursa uma universidade, tem uma profissão "boa", tudo o que Jano sonhara para o filho rebelde.

Lavo, lavra, trabalha, escava na memória a história do amigo:

Li a carta de Mundo num bar do beco das Cancelas, onde encontrei refúgio contra o rebuliço do centro do Rio e as discussões sobre o destino do país. Uma carta sem data, escrita numa clínica de Copacabana, aos solavancos e com uma caligrafia miúda e trêmula que revelava a dor do meu amigo. (HATOUM, 2005, p.9)

A narrativa já começa em "cinzas", demonstrando a dor e o fracasso do amigo. Esse será, então, o dispositivo para a rememoração da história de Mundo, história esta que Lavo vivenciou de perto. A partir das memórias individuais e coletivas, Lavo vai traçando a tessitura da obra.

Não obstante, termina com Mundo escrevendo a carta para o amigo “(...) Pensei em reescrever minha vida de trás para frente, de ponta-cabeça, mas não posso, mal consigo rabiscar, as palavras são manchas no papel, e escrever é quase um milagre...” (HATOUM, 2005, p.311).

\section{O RETORNO CÍCLICO}

Observamos assim um movimento cíclico, essas cinzas que segundo o Dicionário de Símbolos, de Chevalier e Gheerbrant “[...] entre os maia-quichés, a cinza parece efetivamente ter uma função mágica, ligada à germinação e ao retorno cíclico da vida manifestada: os heróis Gêmeos do Popol-Vuh transformam-se em cinzas antes de ressuscitar como o pássaro Fênix". (2009, p. 248). A Fênix ressurge, não morre, não é esquecida. A narração de Lavo é um trabalho de não esquecimento.

Alduíno Arana, o artista no qual Mundo se inspira, é visto pelos outros como um charlatão. Em conversa com Lavo Ranulfo fala sobre a identidade desse artista: "O menino Alduíno, o artista e o Arana. Três numa só pessoa. É o maior artista deste nosso fabuloso hemisfério, mas só ele pensa assim”. (HATOUM, 2005, p. 101).

Mundo é influenciado por Arana sem saber que no fundo os dois tem uma relação mais forte, bem mais forte da qual Mundo teria com Jano. Afinal, a relação que ambos tem é 
consanguínea. No entanto, mesmo após todas as divergências entre os dois, Lavo se questiona acerca dos pensamentos do amigo:

Todas as críticas de Mundo ao artista da ilha tinham sido insinceras? Depois de tudo o que acontecera entre os dois, das divergências em relação à arte e à vida, ao modo de olhar o Amazonas, Mundo ia retornar à cidade, expor seus trabalhos no ateliê de Arana, e quem sabe, se hospedar na casa dele. Ia capitular, voltar ao tempo da juventude, da ingenuidade, da crença fervorosa e cega no artista da ilha. (HATOUM, 2016, p. 258)

Toda essa crítica vem acompanhada de um fator histórico, quando Mundo retornasse à Manaus, não reconheceria a cidade, mudada, arrasada a pretexto de progresso:

Em poucos anos Manaus crescera tanto, que Mundo não reconheceria certos bairros, ele só presenciara o começo da destruição; não chegara a ver a "reforma urbana" do coronel Zanda, as praças do centro, como a nove de Novembro, serem rasgadas por avenidas e terem todos os seus monumentos saqueados; não viu sua casa ser demolida, nem o Hotel gigantesco erguido no mesmo lugar. Arana, hábil e sagaz, percebeu que o mogno era valioso no Brasil e no mundo e então, juntou a matéria de sua arte a um empreendimento suspeitoso, passou a exportar objetos e móveis de madeira nobre. (HATOUM, 2005, p. 258-59)

A escrita do texto funciona como uma denúncia ao que acontece em Manaus, essa destruição de que Mundo foi poupado de presenciar, mas que ele já sabia que aconteceria. As palavras das personagens indignam; reclamam. Como bem diz Tupiassú, "seus livros são a prova dessa reclamação verídica atada às amarras do fíccional” (2016, p. 164).

As palavras de Hatoum, além de denunciar essas mazelas, também trazem a doçura de uma região, nos transporta para a floresta, onde podemos sentir os aromas e os ventos vindos do rio. Ao leitor não resta mais nada, a não ser se entregar e embarcar nessa viagem, com um mister de sentimentos e nas palavras de Nassar: "em literatura, quando você lê um texto que não toca o coração é que alguma coisa está indo para as cucuias" (NASSAR apud TUPIASSÚ, 2016, p. 166).

Ao tratar da linguagem utilizada por Hatoum em suas obras, Beth Brait (2008) argumenta que é possível observar um trabalho singular com a língua, que representa uma "dimensão que conduz a um de seus traços característicos: relatos cerzidos com os fíos de reminiscências colhidas na rica experiência individual e coletiva, no fértil imaginário que as alimenta" (BRAIT, 2008, p. 34).

No romance, podemos variar relativamente a nossa interpretação da personagem; mas o escritor lhe deu, desde logo, uma linha de coerência fixada para sempre, delimitando a curva da sua existência e a natureza do seu modo-de-ser. (CANDIDO et. al. 2014, p.59). A estética da recepção assegura no leitor a materialização do texto e a atualização do mesmo. 
Com isso, segundo Hatoum,

Os escritores têm uma concepção - mais ou menos clara - de cada personagem que vai inventar. O que ela fala? Qual é o tom dessa voz narrativa? Como essa personagem pensa e age? Como ela participa da rede de relações intrincadas que moldam uma trajetória de vida e seu destino? (HATOUM in BRAIT, 2017, p.138)

Assim é a construção de uma personagem, o autor tece com muito cuidado cada passagem, que cabe ao leitor ir preenchendo as lacunas que vão sendo deixadas.

Nem sempre as suposições ou intenções de um escritor são confirmadas pelos leitores. O autor convida seus leitores a acompanhar a trajetória de vida das personagens, a refletir sobre elas, a vê-las como seres fictícios, mas nem por isso menos verdadeiros enquanto durar a leitura. (HATOUM apud BRAIT, 2017, p.140)

\section{CONSIDERAÇÕES FINAIS}

Como se vê, a ideia de "Mundo", o personagem que está em primeiro plano e que remete a essa ideia de abarcar todas as possibilidades fora de seu próprio território- conforto, as demais personagens também têm a noção de que estão em partes distintas do mundo, a partir do momento em que cada um desempenha uma função ou uma atividade nesses diferentes mundos. A reunião de todos eles amplia a ideia da diversidade e multiculturalidade do mundo, e também as suas complexidades.

Desse modo, percebemos que o autor utilizou os nomes dessas personagens para reforçar a ideia de Mundo, o personagem principal da obra. Essa ideia nos remete à questão cosmopolita, assim como os românticos de Jena queriam a expansão das relações da Alemanha do século XIX.

Pela abertura do texto literário, abertura esta que a própria poética possibilita, percebemos que a escolha dos nomes das personagens dialoga com cada papel que elas desempenham na diégese.

\section{REFERÊNCIAS}

BRAIT, Beth. A linguagem da memória. Revista Língua Portuguesa, n. 31. São Paulo: Editora Segmento, 2008, p. 34-35

A personagem. 9.ed. São Paulo: Contexto, 2017, p. 176.

CHEVALIER, Jean.; GHEERBRANT, Alain. Dicionário de símbolos. Tradução de Vera da Costa e Silva et alii. Rio de Janeiro: José Olympio, 2009. 
HATOUM, Milton. Cinzas do Norte. São Paulo: Companhia das Letras, 2005.

KURY, Mário da Gama. Dicionário de mitologia grega e romana. $8^{a}$ Ed. Rio de Janeiro: Jorge Zahar Ed., 2008.

MESCHONNIC, Henri. Em prol da poética. In: Teoria da literatura em suas fontes, vol.1/seleção, introdução e revisão técnica, Luiz Costa Lima. Rio de Janeiro: Civilização Brasileira, 2002.

MORGENSTERN, Karl. Über das Wesen des Bildungsromans (1820). In: SELBMANN, Rolf. (ed.) Zur Geschichte des deutschen Bildungsromans. Darmstadt: Wiss. Buchgesellschaft, 1988, p. 55-72 (Wege der Forschung, 640).

PRESSLER, Gunter K.. O Romance de Formação na Literatura Amazônica. In: I Encontro ABRALIC na Amazônia, 5 a 9 de novembro de 2002., 2002, Belém. ANAIS do I Encontro ABRALIC na Amazônia. Belém: UNAMA 2002, 2002. v. 1

SAFRANSKI. Rüdiger. Romantismo: uma questão alemã. Tradução: Rita Rios. São Paulo: Estação Liberdade, 2010.

SCHMID, Wold. Elemente der Narratologie. De Gruyter, Berlin,2005.

TUPIASSÚ, Amarílis. Escritores da Amazônia e de outros nortes: uma leitora inquieta. Belém: Secult, 2016.

VOLOBUEF, Karin. Frestas e arestas. A prosa de ficção do romantismo na Alemanha e no Brasil. São Paulo: Fundação Editora da UNESP (FEU) 1999. 